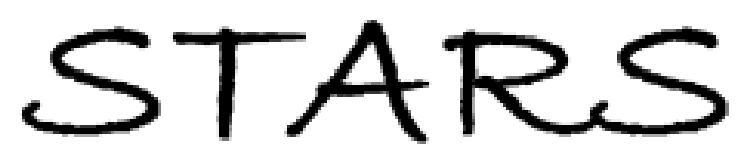

University of Central Florida

STARS

Faculty Bibliography 2000s

Faculty Bibliography

$1-1-2007$

\title{
Mechanical crystallization of Fe-based amorphous alloys
}

Satyajeet Sharma

University of Central Florida

C. Suryanarayana

University of Central Florida

Find similar works at: https://stars.library.ucf.edu/facultybib2000

University of Central Florida Libraries http://library.ucf.edu

This Article is brought to you for free and open access by the Faculty Bibliography at STARS. It has been accepted for inclusion in Faculty Bibliography 2000 s by an authorized administrator of STARS. For more information, please contactSTARS@ucf.edu.

\section{Recommended Citation}

Sharma, Satyajeet and Suryanarayana, C., "Mechanical crystallization of Fe-based amorphous alloys" (2007). Faculty Bibliography 2000s. 7638.

https://stars.library.ucf.edu/facultybib2000/7638

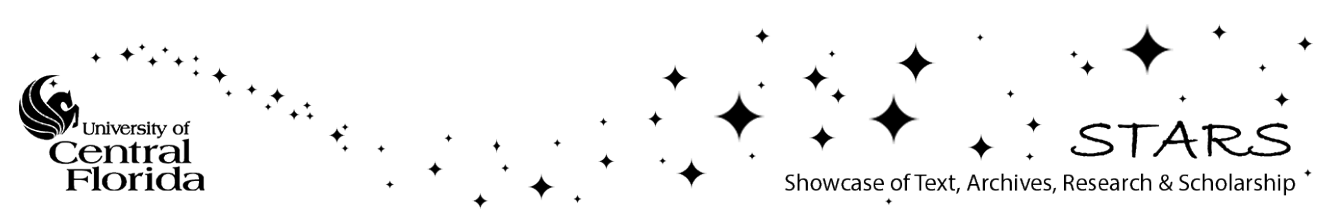




\section{Mechanical crystallization of Fe-based amorphous alloys}

Cite as: J. Appl. Phys. 102, 083544 (2007); https://doi.org/10.1063/1.2800840

Submitted: 03 July 2007 . Accepted: 29 August 2007 . Published Online: 30 October 2007

Satyajeet Sharma, and C. Suryanarayana

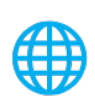

\section{ARTICLES YOU MAY BE INTERESTED IN}

Formation of an amorphous phase and its crystallization in the immiscible $\mathrm{Nb}$-Zr system by mechanical alloying

Journal of Applied Physics 114, 153512 (2013); https://doi.org/10.1063/1.4825325

Preparation of "amorphous" $\mathrm{Ni}_{60} \mathrm{Nb}_{40}$ by mechanical alloying

Applied Physics Letters 43, 1017 (1983); https://doi.org/10.1063/1.94213

Formation of amorphous alloys by the mechanical alloying of crystalline powders of pure metals and powders of intermetallics

Applied Physics Letters 49, 146 (1986); https://doi.org/10.1063/1.97206

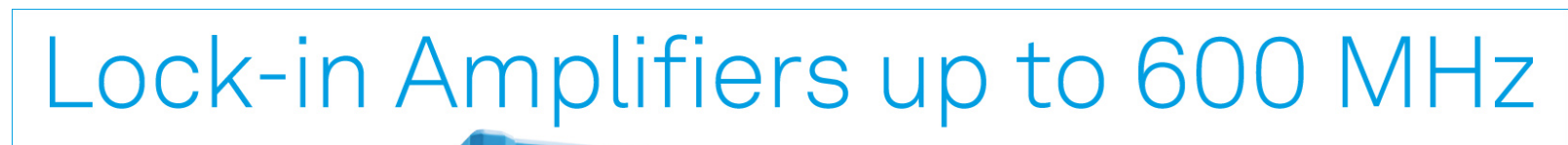

starting at

\section{$\$ 6,210$}

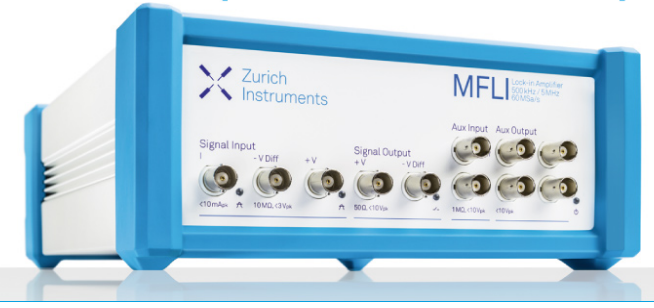

J. Appl. Phys. 102, 083544 (2007); https://doi.org/10.1063/1.2800840

(c) 2007 American Institute of Physics.
102,083544 


\title{
Mechanical crystallization of Fe-based amorphous alloys
}

\author{
Satyajeet Sharma and C. Suryanarayana ${ }^{a)}$ \\ Department of Mechanical, Materials and Aerospace Engineering, University of Central Florida, \\ Orlando, Florida 32816-2450, USA
}

(Received 3 July 2007; accepted 29 August 2007; published online 30 October 2007)

\begin{abstract}
Mechanical alloying of a number of blended elemental powders of Fe-based alloy systems containing four or five components was undertaken to determine if amorphous phases could be produced and also to compare the glass-forming ability achieved by mechanical alloying and that obtained by solidification-processing methods. Amorphous phase formation was achieved in all the alloy systems investigated, the time for the amorphous phase formation being a function of the glass-forming ability of the alloy system investigated. However, in some alloy systems it was noted that on milling, beyond the time required for the formation of the amorphous phase, the amorphous phase started to crystallize, a phenomenon designated as mechanical crystallization. The present paper specifically discusses the results of mechanical crystallization obtained in the $\mathrm{Fe}_{42} \mathrm{Ge}_{28} \mathrm{Zr}_{10} \mathrm{~B}_{20}$ and $\mathrm{Fe}_{42} \mathrm{Ni}_{28} \mathrm{Zr}_{10} \mathrm{C}_{10} \mathrm{~B}_{10}$ alloy systems as representatives of the typical quaternary and quinary (five-component) systems, respectively. In the case of the quaternary system, mechanical crystallization led to the formation of a supersaturated solid solution of all the solute elements in Fe, while in the quinary system, a mixture of the solid solution and intermetallic phases has formed. The possible reasons for mechanical crystallization and the reasons for the differences in the behavior of the quaternary and quinary systems are discussed. (C) 2007 American Institute of Physics.
\end{abstract}

[DOI: $10.1063 / 1.2800840]$

\section{INTRODUCTION}

Amorphous alloys or metallic glasses are solid alloys in which the constituent atoms are arranged in a random manner with no long-range periodicity. Since their first synthesis in a Au-Si eutectic alloy in 1960 by Klement et al., ${ }^{1}$ metallic glasses have been synthesized in a number of binary and higher-order alloy systems in the form of thin ribbons by rapid solidification methods. ${ }^{2-6}$ Interest in these glassy materials has been mainly due to the attractive combination of physical, chemical, mechanical, and magnetic properties of these alloys and their commercial applications. However, during the last several years, the materials science community has focused its attention on bulk metallic glasses (BMGs), ${ }^{7-11}$ glassy alloys that could be produced in large section thicknesses or diameters reaching several tens of millimeters. The largest section thickness (or diameter) that could be achieved is a function of the base metal and alloy composition, amongst other parameters. The largest rod diameter obtained in Fe-based BMGs is only about $16 \mathrm{~mm},{ }^{12}$ while the largest diameter of $72 \mathrm{~mm}$ that has been achieved in BMGs is in a Pd-10 at. \% Ni-30 at. \% Cu-20 at. \% P alloy. ${ }^{13}$ Ability to produce glassy alloys in larger section thicknesses enables exploitation of these advanced materials for a variety of different applications. Since metallic glasses are inherently metastable they tend to transform into the equilibrium crystalline phases on annealing them. Some important parameters that need to be controlled to achieve the desired microstructure and constitution are the temperature and time for any given alloy system. We have recently observed that crystallization of metallic amorphous alloys

${ }^{a)}$ Electronic mail: csuryana@mail.ucf.edu could also be achieved during mechanical alloying of blended elemental powders for times longer than those required for amorphous phase formation.

Mechanical alloying (MA) is another powerful nonequilibrium processing technique to produce metastable materials. $^{14,15}$ It is a powder processing method in which metastable phases can be produced through repeated cold welding, fracturing, and rewelding of powder particles in a high-energy ball mill. The metastable phases produced include supersaturated solid solutions, quasicrystalline and crystalline intermetallic phases, and amorphous alloys. Metallic amorphous alloys have been produced by MA starting from either blended elemental metal powders or prealloyed powders. These amorphous alloy powders could be subsequently consolidated to full density in the temperature range between the glass transition temperature and the crystallization temperature, where the amorphous phase has a very low viscosity. Consequently, this route overcomes the limitation of section thickness imposed during solidification-processing methods. As a part of detailed investigations on the synthesis and characterization of Fe-based BMG compositions by MA, we have observed that amorphous powders get crystallized on continued milling at times beyond those required for the formation of the amorphous phase. This phenomenon is referred to as mechanical crystallization.

There have been some reports of formation of a crystalline phase after the formation of an amorphous phase during milling of metal powders. ${ }^{14,15}$ High-energy milling of $\mathrm{Fe}-$ based glassy ribbons obtained by rapid solidification processing has been shown to lead to crystallization of the glassy phase. ${ }^{16}$ It was argued that crystallization of the metallic glasses induced by high-energy ball milling was not restricted to thermal processes, but can be related to the chemi- 
cal composition of the glassy alloy. Differences in the crystallization temperatures and kinetics were noted when meltspun $\mathrm{Fe}-\mathrm{Mo}-\mathrm{Si}-\mathrm{B}$ glassy alloy ribbons were subjected to crystallization studies under pressure. ${ }^{17}$ Cyclic crystallineamorphous-crystalline transformations have also been reported to occur in prealloyed $\mathrm{Co}-\mathrm{Ti}$ and $\mathrm{Zr}_{2} \mathrm{Ni}$ alloy powders subjected to MA. ${ }^{18-21}$ It was noted that atomic displacements due to heavy plastic deformation and enhancement of atomic mobility during plastic deformation processes are possible mechanisms for mechanical crystallization in $\mathrm{Al}-\mathrm{Fe}-\mathrm{Gd}$ metallic glasses. ${ }^{22,23}$ Patil et al. ${ }^{24}$ reported that blended elemental Fe-based alloy powders with an average composition of $\mathrm{Fe}_{60} \mathrm{Co}_{8} \mathrm{Zr}_{10} \mathrm{Mo}_{5} \mathrm{~W}_{2} \mathrm{~B}_{15}$ became amorphous when milled in a high-energy SPEX mill for $20 \mathrm{~h}$. A supersaturated solution of $\alpha$-Fe was formed in the initial stages of milling which eventually became amorphous. Further milling, up to $50 \mathrm{~h}$, led to primary crystallization of the amorphous phase resulting in the formation of the $\alpha$-Fe solid solution phase with a lattice parameter different from that formed in the early stages of milling. A crystalline phase was also reported to form on milling Ti-based alloy powders after the formation of an amorphous phase. This crystalline phase was, however, later identified to be a contaminant TiN phase. ${ }^{25,26}$

In this paper we will demonstrate that mechanical crystallization of amorphous alloys occurs in Fe-based BMG compositions. It will be also shown that this phenomenon is not as restricted as it was earlier reported or thought to be, but that it is much more general. The details of crystallization will, however, be different depending on the alloy system, and consequently the nature of the crystalline phase(s) will be different. Mechanical crystallization can be observed during MA in almost all alloy systems under appropriate milling conditions. In this article we will discuss two specific alloy systems to support this hypothesis.

\section{EXPERIMENTAL PROCEDURE}

Appropriate amounts of the pure elemental powders ( $\geqslant 99.9 \%$ purity) of $\mathrm{Fe}, \mathrm{Ge}, \mathrm{Ni}, \mathrm{Zr}, \mathrm{C}$, and $\mathrm{B}$ were weighed and mixed together to obtain the desired composition of $\mathrm{Fe}_{42} \mathrm{Ge}_{28} \mathrm{Zr}_{10} \mathrm{~B}_{20}$ and $\mathrm{Fe}_{42} \mathrm{Ni}_{28} \mathrm{Zr}_{10} \mathrm{C}_{10} \mathrm{~B}_{10}$ (the subscripts represent the atomic percentage of the elements in the powder mix). MA was conducted in a high-energy SPEX 8000 mixer mill using hardened steel vial and balls. For each experiment, $10 \mathrm{~g}$ of the blended elemental powder mix and $100 \mathrm{~g}$ of stainless steel balls were loaded into the milling container, thus maintaining a ball-to-powder weight ratio of 10:1 during milling. The weighing, blending, loading, and unloading of the powders were carried out inside a glovebox with a controlled atmosphere of argon gas, so as to minimize powder contamination. The phase evolution during milling was monitored by x-ray diffraction (XRD) using a Rigaku x-ray diffractometer with $\mathrm{Cu} K \alpha$ radiation $(\lambda=0.15406 \mathrm{~nm})$ at $40 \mathrm{kV}$ and $35 \mathrm{~mA}$ settings. The XRD patterns were recorded in the $2 \theta$ range of $30^{\circ}-90^{\circ}$. Identification of the phases present and calculation of the lattice parameter were done using standard XRD procedures. ${ }^{27}$

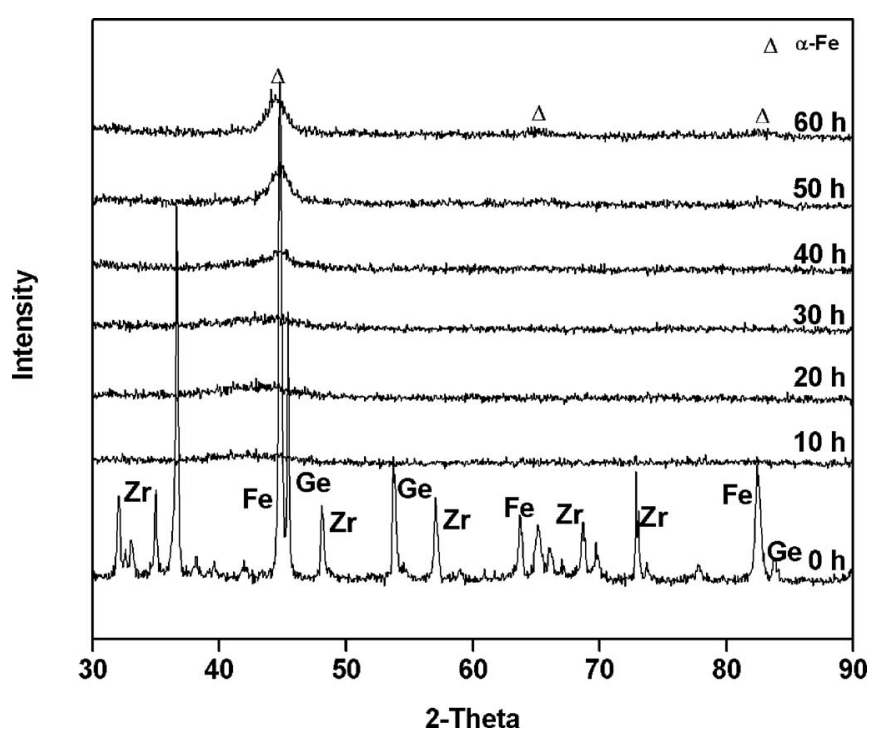

FIG. 1. XRD patterns of blended elemental powder mix of $\mathrm{Fe}_{42} \mathrm{Ge}_{28} \mathrm{Zr}_{10} \mathrm{~B}_{20}$ as a function of milling time. Note that the amorphous phase forms on milling the powder blend for $10 \mathrm{~h}$ and that the amorphous phase is stable up to about $30 \mathrm{~h}$. Milling for times longer than this resulted in mechanical crystallization. Formation of $\alpha$-Fe solid solution with a slight increase in the lattice parameter is seen at $60 \mathrm{~h}$ of milling time.

\section{RESULTS}

Figure 1 shows the structural evolution in the blended elemental powder mixture of $\mathrm{Fe}_{42} \mathrm{Ge}_{28} \mathrm{Zr}_{10} \mathrm{~B}_{20}$ as a function of milling time. All the XRD peaks expected of the constituent metallic elements $(\mathrm{Fe}, \mathrm{Ge}$, and $\mathrm{Zr}$ ) are present in the as-blended mixture ( $0 \mathrm{~h}$ milling time). Diffraction peaks of B are not seen due to its amorphous nature and/or its low scattering factor. It is noted that amorphous phase formation is complete on milling the powder blend for $10 \mathrm{~h}$, as seen by the presence of a broad and diffuse peak at the angular position where the $(110)_{\mathrm{Fe}}$ peak is expected to be present in the powder blend. But, as noted earlier, ${ }^{28}$ in the very early stages of milling, formation of intermetallics was observed. The amorphous phase continued to be present until about $30 \mathrm{~h}$ of milling, suggesting that the amorphous phase produced is quite stable. However, on continued milling, it became unstable and precipitation of an $\alpha$-Fe solid solution is noted, as evidenced by the diffuse peak becoming sharper on milling the powder for about $40 \mathrm{~h}$. This indicates the beginning of crystallization of the amorphous phase, or mechanical crystallization. It is also noted that during the initial stages of mechanical crystallization, the diffuse peak corresponding to $(110)_{\mathrm{Fe}}$ has shifted to lower $2 \theta$ values, indicating that the lattice is expanding which with further milling shifts toward the original position at $40 \mathrm{~h}$. Even at this stage, the peak is still at a slightly lower angle, indicating formation of a solid solution of $\mathrm{Fe}$ with the alloying elements. At a milling time of $60 \mathrm{~h}$, formation of the $\alpha$-Fe solid solution with a bcc structure is observed as indicated by the appearance of sharp and intense $(110)_{\mathrm{Fe}}$ and relatively low intensity $(200)_{\mathrm{Fe}}$ and $(211)_{\mathrm{Fe}}$ peaks at $2 \theta$ values of $44.35^{\circ}, 63.55^{\circ}$, and $82.35^{\circ}$, respectively. Figure 2 shows the XRD patterns of the quaternary alloy powder milled for 10 and $60 \mathrm{~h}$, indicating the significant change in the nature of the two patterns. Note 


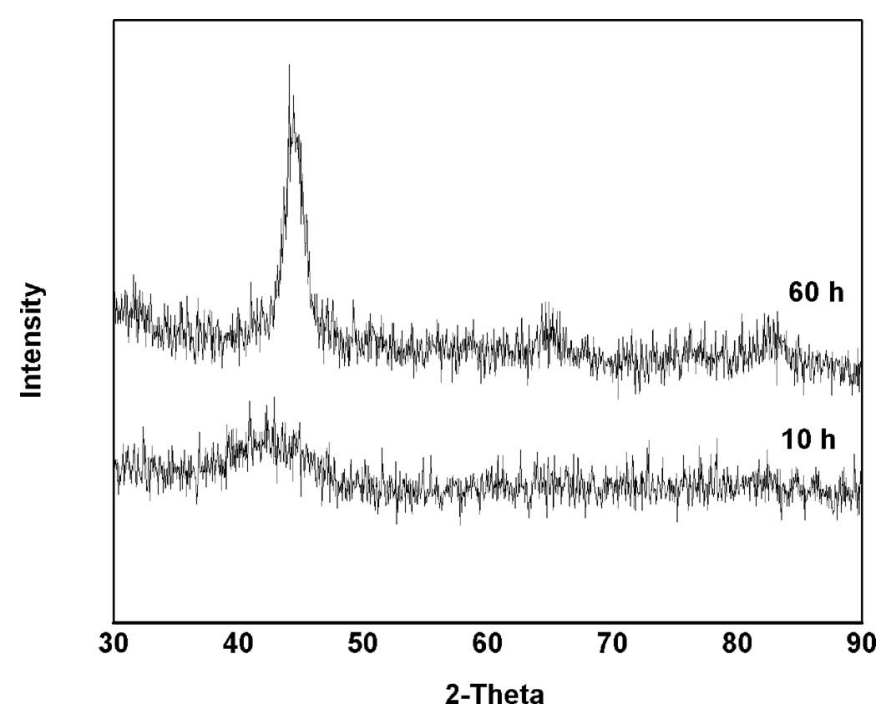

FIG. 2. X-ray diffraction patterns of the $\mathrm{Fe}_{42} \mathrm{Ge}_{28} \mathrm{Zr}_{10} \mathrm{~B}_{20}$ powder mix milled for 10 and $60 \mathrm{~h}$. While the powder mix milled for $10 \mathrm{~h}$ clearly shows that an amorphous phase had formed, the powder milled for $60 \mathrm{~h}$ clearly shows mechanical crystallization. Also note the significant shift in the diffraction maximum of the amorphous phase (corresponding to the 110 peak of the $\alpha$-Fe solid solution) from the clear 110 peak in the crystalline phase at $60 \mathrm{~h}$. This significant shift manifests in the change in lattice parameter and consequently the solute content in the phases.

clearly the phenomenon of mechanical crystallization in the powder milled for $60 \mathrm{~h}$. A close examination of this diffraction pattern in Fig. 2 suggests that the $\alpha$-Fe phase exhibits an increase in the lattice parameter. The lattice parameter, calculated on the basis of the $(110)_{\mathrm{Fe}}$ peak, at this stage is about $0.2878 \mathrm{~nm}$, against the lattice parameter of $a=0.28665 \mathrm{~nm}$ for pure Fe. ${ }^{29} \mathrm{~A}$ similar behavior was noted in another multicomponent $\mathrm{Fe}$-based alloy powder. ${ }^{24}$

Figure 3 shows the XRD patterns of the

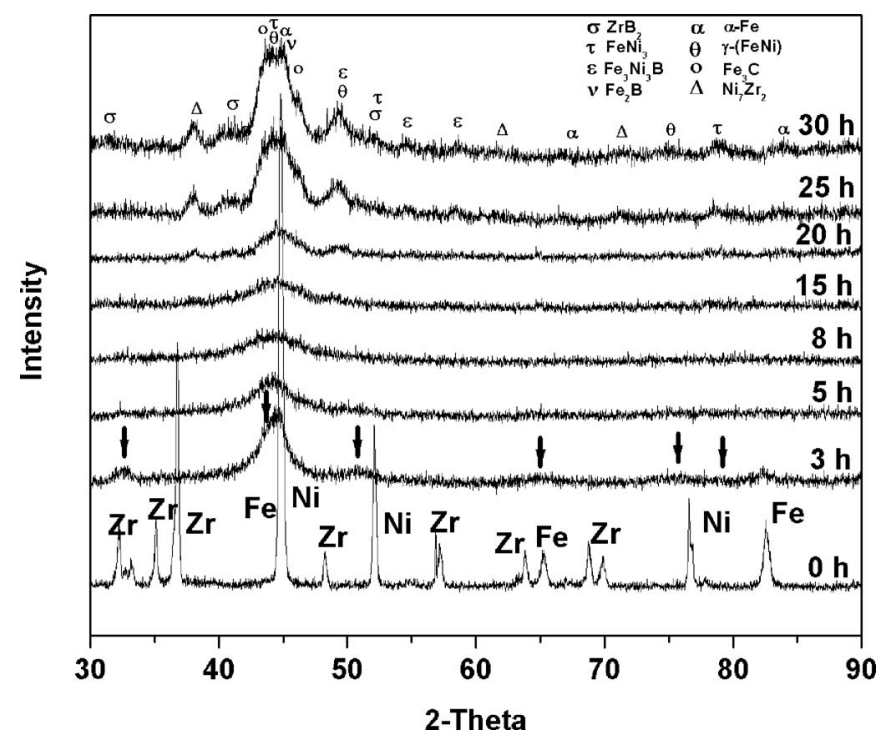

FIG. 3. XRD patterns of blended elemental powder mix of $\mathrm{Fe}_{42} \mathrm{Ni}_{28} \mathrm{Zr}_{10} \mathrm{C}_{10} \mathrm{~B}_{10}$ as a function of milling time. Note that the amorphous phase formed on milling the powder for $8 \mathrm{~h}$ and is found to be stable until $15 \mathrm{~h}$. Mechanical crystallization is noted to occur around $25 \mathrm{~h}$. The intensities of the crystalline peaks of the different phases increased beyond this milling time. Also note the formation of intermetallics during the early hours of milling the powder for $3 \mathrm{~h}$, indicated by arrows.

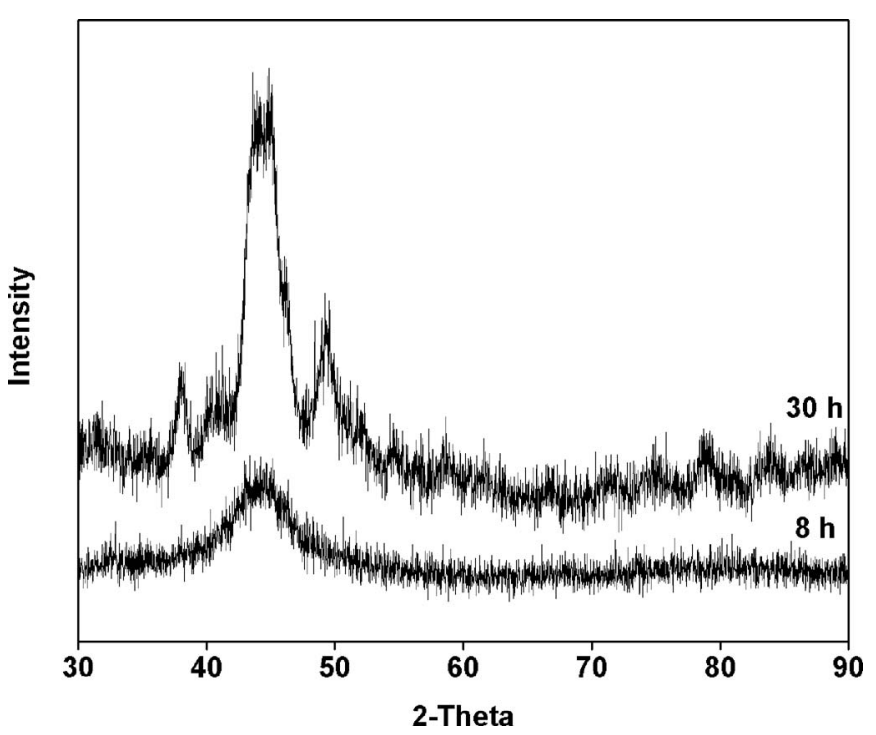

FIG. 4. XRD patterns of the $\mathrm{Fe}_{42} \mathrm{Ni}_{28} \mathrm{Zr}_{10} \mathrm{C}_{10} \mathrm{~B}$ 10 powder blend milled for 8 and $30 \mathrm{~h}$. The shift in the diffraction maximum of the amorphous phase $(8 \mathrm{~h})$ and the $(110)_{\mathrm{Fe}}$ peak position $(30 \mathrm{~h})$ is seen to be less as compared to that in Fig. 2.

$\mathrm{Fe}_{42} \mathrm{Ni}_{28} \mathrm{Zr}_{10} \mathrm{C}_{10} \mathrm{~B}_{10}$ powder mix as a function of milling time. As noted earlier, the as-blended powder mix showed the presence of all the diffraction peaks expected from the metallic elements. Formation of an amorphous phase is noted on milling the powder blend for $8 \mathrm{~h}$. Also, during the early stages of milling, formation of intermetallics is observed as indicated by the low intensity relatively sharp peaks. The homogeneous amorphous phase in this powder blend is stable until about $15 \mathrm{~h}$ of milling. On milling the powders for a longer time, formation of some crystalline phases is noted, a result of mechanical crystallization of the amorphous phase. But, mechanical crystallization is clearly evident on milling the powder blend beyond about $30 \mathrm{~h}$, as indicated by the relatively intense diffraction peaks of different phases. Similar to what was noted in Fig. 1, here also we observe that, with continued milling, the $(110)_{\mathrm{Fe}}$ peak has shifted to lower $2 \theta$ angles, signifying an increase in the lattice parameter of the solid solution phase at the initial stages of milling. However, due to the overlap of diffraction peaks of the different phases, the lattice parameter of the $\alpha$-Fe solid solution phase could not be determined in this case. Similar observations were noted in other Fe-based systems such as $\mathrm{Fe}_{42} \mathrm{Al}_{28} \mathrm{Zr}_{10} \mathrm{C}_{10} \mathrm{~B}_{10}$ and $\mathrm{Fe}_{42} \mathrm{Ni}_{28} \mathrm{Zr}_{6} \mathrm{Nb}_{4} \mathrm{~B}_{20} \cdot{ }^{30}$ Figure 4 shows the XRD patterns of this powder mix milled for 8 and $30 \mathrm{~h}$, showing clearly the phenomenon of mechanical crystallization in the latter pattern.

Thus, by observing the XRD patterns of the quaternary and quinary Fe-based alloy systems investigated here, the general sequence of phase formation during milling may be summarized as:

$$
\begin{aligned}
\text { BE powder } & \rightarrow \text { intermetallics } \rightarrow \text { amorphous phase } \\
& \rightarrow \text { mechanical crystallization }
\end{aligned}
$$

- But, the nature and sequence of the crystalline phases formed as a result of mechanical crystallization are different in the two alloy systems. While a solid solution phase had 
formed in the $\mathrm{Fe}_{42} \mathrm{Ge}_{28} \mathrm{Zr}_{10} \mathrm{~B}_{20}$ powder mix, a mixture of solid solution and intermetallic phases had formed in the $\mathrm{Fe}_{42} \mathrm{Ni}_{28} \mathrm{Zr}_{10} \mathrm{C}_{10} \mathrm{~B}_{10}$ powder mix.

\section{DISCUSSION}

\section{A. Amorphous phase formation}

The XRD patterns presented clearly confirm the formation of amorphous phases in both the powder blends, which on continued milling transformed into the crystalline phases. Such observations have been reported earlier in some systems, as noted in the Introduction. But, there are some points which are significantly different between the earlier observations and our present findings. The most important difference is that we had started with blended elemental powders in our investigation. Milling of these powder blends resulted in the formation of an amorphous phase, which subsequently showed mechanical crystallization. However, in the earlier studies either rapidly solidified glassy ribbons ${ }^{16,17}$ or prealloyed crystalline powders ${ }^{18,21}$ were the starting materials. But, first of all let us look at the reasons for the formation of the amorphous phase on milling the powder blends.

In the initial stages of milling, alloying occurs among the constituent elements in the powder blend. This is facilitated by the chemical interaction of the different elements, thus leading to the formation of solid solution and intermetallic phases in the present alloy systems. It is also well known that MA introduces a high density of different crystal defects, including dislocations, grain boundaries, stacking faults, and others. ${ }^{14,15}$ All these defects increase the free energy of the system. Further, because of the complex crystal structures and ability of the intermetallics to get disordered by mechanical deformation, the free energy of such systems can be further raised to a level above that of a hypothetical glassy phase. Consequently, the crystalline phase gets destabilized and amorphization is favored.

Amorphization is also facilitated by the strain energy introduced into the alloy system due to the size differences between the solvent and solute elements. It was noted in both Figs. 1 and 3 that the $\alpha$-Fe solid solution phase shows an increase in the lattice parameter in the early stages of milling. This is because of dissolution of the metallic elements (Ge: $0.244 \mathrm{~nm}, \mathrm{Zr}: 0.3186 \mathrm{~nm}$, and Ni: $0.2492 \mathrm{~nm}$ ) which have an atomic size larger than that of $\mathrm{Fe}(0.2482 \mathrm{~nm})$. Further, both $\mathrm{C}(0.154 \mathrm{~nm})$ and $\mathrm{B}(0.188 \mathrm{~nm})$ dissolve in the $\mathrm{Fe}$ lattice interstitially and consequently increase the lattice parameter of the solid solution phase. Once the threshold amount of distortion of the lattice is achieved due to the size mismatch between the solvent and solute atoms, the crystalline lattice becomes destabilized and amorphization is expected to occur. ${ }^{31,32}$ This argument is supported by the lattice parameter variation in the present study, which increased in the early stages of milling and then started to decrease once crystallization of the glassy phase had occurred. The increase of lattice parameter in the initial stages of milling leads to increase of lattice strain and once it reaches a critical value, glass formation occurs. But, on continued milling mechanical crystallization occurs resulting in the formation (precipitation) of a crystalline phase. Since this requires long-range diffusion of atoms to form the solid solution or intermetallic phase, partition of alloying elements takes place and consequently the remaining amorphous phase contains a higher concentration of solute elements. As a result of this, the lattice parameter of the solid solution phase decreases. Thus, the decrease of the lattice parameter on crystallization of the glassy phase can be attributed to depletion of the solute atoms from the solid solution phase to form the solid solution/ intermetallics.

\section{B. Mechanical crystallization}

Mechanical crystallization has been clearly observed in the present investigation as shown in Figs. 2 and 4. Let us now look at the possible reasons for this phenomenon. There can be many reasons for the formation of a crystalline phase after the formation of a glassy phase. The important ones are (1) rise in temperature to a level above that of the crystallization temperature of the glassy phase, (2) powder contamination due to which a crystalline phase may be stabilized in preference to the glassy phase, (3) phenomenon of inverse melting, or (4) basic thermodynamic considerations.

\section{Temperature rise}

Milling of powders involves severe plastic deformation and this results in a local rise of powder temperature. Even though the temperature rise in the powders during milling could be large in a highly localized area, the highest global temperature rise reported is not more than about $200 \mathrm{~K}^{15}$ Since the crystallization temperatures of most Fe-based glasses are in the range of about $800-1000 \mathrm{~K}$, it is most unlikely that the powder during milling has reached this high a temperature. Further, it has been suggested that while room temperature milling can introduce nucleation sites for crystallization, annealing at elevated temperatures is required for observing the phenomenon of crystallization. ${ }^{33}$ Therefore, the small temperature rise can be discounted as a possible reason for crystallization of the amorphous phase during milling.

\section{Powder contamination}

The literature on MA contains several examples of impurity-stabilized crystalline phases, which have formed after the formation of the amorphous phase. ${ }^{25,26,34}$ For example, formation of a fcc crystalline phase after the formation of an amorphous phase was reported in several titaniumbased alloys. ${ }^{25}$ This crystalline phase has subsequently been identified to be not the product of crystallization, but TiN, formed due to exposure of the titanium alloy powder to atmospheric contamination. Since it is noted that the amorphous phase in the $\mathrm{Fe}_{42} \mathrm{Ge}_{28} \mathrm{Zr}_{10} \mathrm{~B}_{20}$ powder mix (Fig. 1) and the $\mathrm{Fe}_{42} \mathrm{Ni}_{28} \mathrm{Zr}_{10} \mathrm{C}_{10} \mathrm{~B}_{10}$ powder mix (Fig. 3) and other Febased amorphous alloy systems have crystallized into the expected equilibrium phases (solid solution and intermetallic phases), it can be safely assumed that the crystalline phase formed after the formation of the amorphous phase in the present case is not impurity stabilized. 


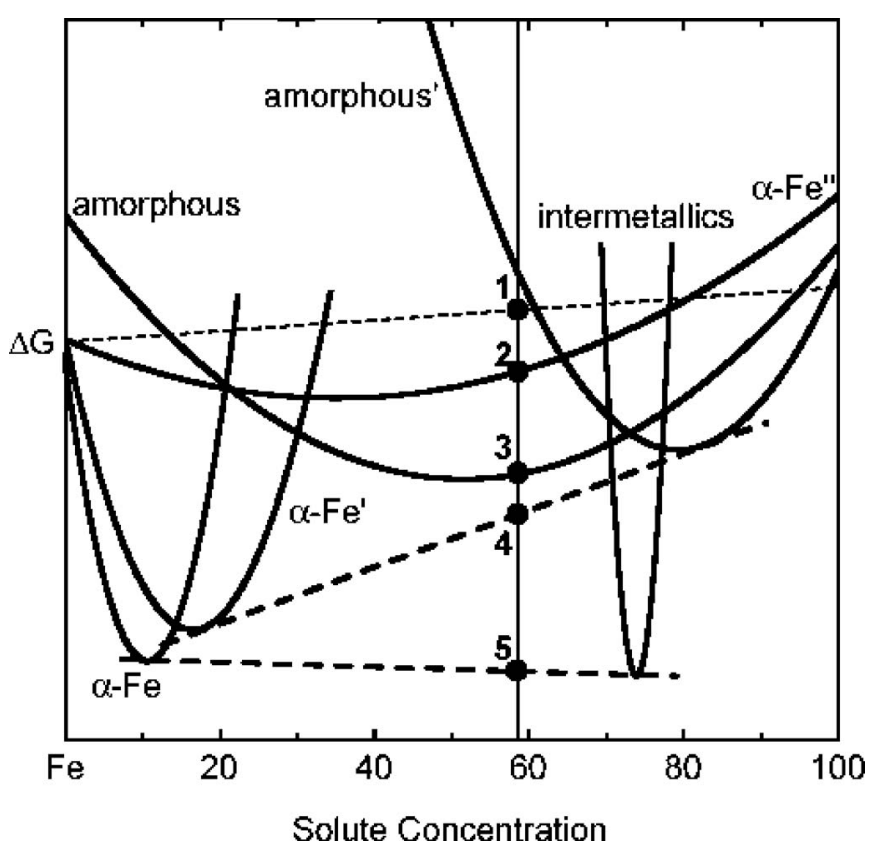

FIG. 5. Hypothetical free energy vs composition diagram to explain the mechanism of mechanical crystallization in the $\mathrm{Fe}_{42} \mathrm{Ni}_{28} \mathrm{Zr}_{10} \mathrm{C}_{10} \mathrm{~B}_{10}$ system. Note that point 1 represents the free energy of the blended elemental powders. Similarly, point " 2 " represents formation of the $\alpha-\mathrm{Fe}^{\mathrm{p}}$ " solid solution of all the alloying elements in $\mathrm{Fe}$, point " 3 " formation of the homogeneous amorphous phase, point " 4 " a mixture of the amorphous phase with a different solute content (amorphous') than at 3 and the solid solution $\alpha-\mathrm{Fe}^{\prime}$, and point " 5 " is for the equilibrium situation when the solid solution and intermetallics coexist.

\section{Inverse melting}

Another possible reason of mechanical crystallization could be due to the phenomenon of inverse melting. This is a phenomenon, which was first reported in $\mathrm{Ti}-\mathrm{Cr}$ alloys, ${ }^{35,36}$ but later reported in several other systems also. ${ }^{37,38}$ In this process, heating of a homogeneous metastable bcc solid solution alloy, formed by MA, to higher temperatures produces an amorphous phase polymorphously. On further heating to still higher temperatures, the glassy phase crystallizes into the bcc phase again, i.e., the phenomenon is reversible. However, the conditions required for the occurrence of inverse melting (see Ref. 24 for a detailed discussion) are not met in the present Fe-based alloys and, therefore, this possibility could also be discounted.

\section{Basic thermodynamic considerations}

Since the above possibilities could not satisfactorily explain the formation of a crystalline phase on continued milling of the powder after an amorphous phase had formed, the most likely mechanism that led to amorphization in the first instance and subsequent crystallization can be attributed to introduction of mechanical energy into the system and consequent relative thermodynamic stabilities of the different competing phases or phase mixtures.

Figure 5 represents a schematic free energy versus composition diagram indicating the relative positions of the blended elemental powder mixture, amorphous, solid solution, and "intermetallic" phases. (We have grouped all the possible intermetallic phases in these systems into interme- tallics). In alloy systems with negative heat of mixing, the blended elemental powder mixture has obviously a high free energy (point 1). Therefore, on MA, the blended powder mixture is expected to change into a more stable configuration to reduce its free energy. Thus, the $\alpha$ - $\mathrm{Fe}^{\prime \prime}$ solid solution phase (point 2) containing all the solute elements in $\mathrm{Fe}$ is seen to be forming on milling. Since MA introduces many crystal defects including vacancies, dislocations, grain boundaries, surfaces, and others, the milled powders can contain excess energy. ${ }^{14,15}$ It was clearly shown by us ${ }^{28}$ earlier that intermetallics form in the early stages of milling in many of the Fe-based powder mixtures. And disordering of such intermetallics can also substantially increase the free energy of the system. ${ }^{39}$ Hence, on continued milling, the free energy of the crystalline phase increases to a level above that of the amorphous phase which results in the destabilization of the crystalline phase and the "amorphous" phase (point 3) begins to be stabilized. But, further milling leads to mechanical crystallization resulting in the formation of a solid solution or intermetallics coexisting with the remaining amorphous phase. Since primary crystallization had occurred, the Fe-solid solution will now have a composition different from the original $\alpha-\mathrm{Fe}^{\prime \prime}$ solid solution; let us call this $\alpha-\mathrm{Fe}^{\prime}$. This solid solution will now coexist with the amorphous phase (amorphous') which also has a different composition because of the precipitation of $\alpha-\mathrm{Fe}^{\prime}$ from the original amorphous phase. Point 4 now represents the free energy of the mixture of amorphous' and $\alpha-\mathrm{Fe}^{\prime}$. The lowest free energy for the system will, however, correspond to a condition when a mixture of the equilibrium solid solution $(\alpha-\mathrm{Fe})$ and the intermetallics coexist. This situation is indicated by point 5 in the figure.

\section{Difference in the mechanical crystallization behavior of the two systems}

Examination of Figs. 2 and 4 makes it clear that even though mechanical crystallization has occurred in both the alloy systems investigated, the nature of the crystalline phase formed on further milling the amorphous powder is different. A solid solution phase had formed in the $\mathrm{Fe}_{42} \mathrm{Ge}_{28} \mathrm{Zr}_{10} \mathrm{~B}_{20}$ powder blend, whereas intermetallic phases had formed in the $\mathrm{Fe}_{42} \mathrm{Ni}_{28} \mathrm{Zr}_{10} \mathrm{C}_{10} \mathrm{~B}_{10}$ powder blend, as a result of crystallization of the amorphous phase.

Metallic glasses obtained by rapid solidification processing have been known to crystallize in three different modes. ${ }^{40,41}$ One of them is the polymorphous mode in which the glass transforms into a crystalline phase without a change in composition. The second of them is the eutectic mode in which the glassy phase transforms into a mixture of phases simultaneously. The third possibility is the primary mode in which a solid solution based on the solvent atom precipitates from the glassy phase. The remaining glassy phase could subsequently transform into the equilibrium phases either by a polymorphous or eutectic mode. Examples are available to show that similar transformations occur in mechanically alloyed amorphous powders also. ${ }^{15,34}$

Thus, one can say that primary crystallization had occurred in the $\mathrm{Fe}_{42} \mathrm{Ge}_{28} \mathrm{Zr}_{10} \mathrm{~B}_{20}$ powder blend, whereas eutec- 
tic crystallization had taken place in the $\mathrm{Fe}_{42} \mathrm{Ni}_{28} \mathrm{Zr}_{10} \mathrm{C}_{10} \mathrm{~B}_{10}$ powder blend. Reasons for the differences in the crystallization modes could be related to either the composition of the amorphous phase and/or the conditions under which crystallization of the amorphous phase occurs.

Application of pressures during crystallization has been known to have an important effect on the crystallization mode, kinetics of crystallization, and the nature of the crystallization products. ${ }^{40-42}$ The local pressure generated by the impact of steel balls on the powder during MA has been estimated to be of the order of $6 \mathrm{GPa} \cdot{ }^{15,43,44}$ Because of the generation of these high pressures, several high-pressure polymorphs have also been stabilized by MA of powders. ${ }^{15}$

Let us now consider the effect of pressure on the crystallization behavior of amorphous phases. The nucleation rate, at a temperature $T$, may be written down as

$$
I=I_{0} \exp \left(-\frac{\Delta G_{n}+\Delta E}{R T}\right)=I_{0} \exp \left(-\frac{\Delta G}{R T}\right),
$$

where $\Delta G_{n}$ is the activation energy for nucleation, $\Delta E$ is the diffusion activation energy, $I_{0}$ is a constant, and $R$ is the gas constant. $\Delta G=\Delta G_{n}+\Delta E$ is defined as the nucleation energy that determines the crystallization temperature of an amorphous alloy. $\Delta G_{n}$ can be expressed as

$$
\Delta G_{n}=\frac{16 \pi \sigma^{3}}{3 \Delta G_{v}^{2}}=\frac{16 \pi \sigma^{3}}{3\left(\Delta G_{c}-\Delta G_{a}\right)^{2}},
$$

where $\sigma$ is the interfacial energy between the amorphous alloy and its crystallization product phase, and $\Delta G_{a}$ and $\Delta G_{c}$ represent the molar Gibbs free energies for the amorphous alloy and the corresponding crystalline phase, respectively. Using Eqs. (1) and (2), Yao et al. ${ }^{17}$ derived an expression relating the variation of $\Delta G$ with pressure at a fixed temperature as

$$
\left(\frac{\partial \Delta G}{\partial P}\right)_{T}=-\frac{32 \pi \sigma^{3}}{3\left(\Delta G_{c}-\Delta G_{a}\right)^{3}}\left(v_{c}-v_{a}\right)+\left(\frac{\partial \Delta E}{\partial P}\right)_{T},
$$

where $v_{a}$ and $v_{c}$ are the molar volumes of the amorphous alloy and its crystalline counterpart, respectively. Since the amorphous phase contains more free volume, it may be assumed that $v_{c}<v_{a}$ and $\Delta G_{a}>\Delta G_{c}$. Thus, the first term in Eq. (3) represents the factor that promotes crystallization of the amorphous phase and the second term represents the factor that retards crystallization; the value represented by the second term decreases with increasing pressure. Therefore, higher pressures are expected to promote crystallization when an amorphous alloy transforms polymorphically into a single-phase intermetallic compound or supersaturated solid solution, where long-range diffusion is not required. The increase of the diffusion activation energy with increasing pressure in this case is so small that the nucleation activation energy $\Delta G$ decreases with increasing pressure. However, pressure may retard crystallization of the amorphous alloy when it crystallizes in a eutectic mode, which requires longrange diffusion for atomic rearrangement to form new crystalline phases. In this case, the increase in the diffusion activation energy is so large that the nucleation energy $\Delta G$ increases with an increase in pressure. Therefore, the effects of pressure on crystallization depend on atomic diffusion vis$\grave{a}$-vis crystallization mode.

In our investigations, the amorphous $\mathrm{Fe}_{42} \mathrm{Ge}_{28} \mathrm{Zr}_{10} \mathrm{~B}_{20}$ alloy has crystallized in the primary mode forming an $\alpha$-Fe solid solution, possibly with a composition different from the original solid solution phase that had formed in the early stages of milling. This conclusion was arrived at because of a slight difference in the lattice parameter of the solid solution phase. On the other hand, in the case of the $\mathrm{Fe}_{42} \mathrm{Ni}_{28} \mathrm{Zr}_{10} \mathrm{C}_{10} \mathrm{~B}_{10}$ alloy blend, the XRD plots (Fig. 2) indicate the formation of amorphous' (amorphous phase with a solute content different from the original blend that had amorphized, as a result of precipitation of some crystalline phases), solid solution, and other equilibrium intermetallic phases. The simultaneous formation of these phases suggests that the mode of crystallization in this alloy is possibly eutectic and not primary. Since in both the cases, long-range diffusion was needed to form the crystalline phases, we can conclude that the high pressure experienced by the powder during milling could not possibly explain the primary crystallization in the $\mathrm{Fe}_{42} \mathrm{Ge}_{28} \mathrm{Zr}_{10} \mathrm{~B}_{20}$ powder blend and the eutectic crystallization in the $\mathrm{Fe}_{42} \mathrm{Ni}_{28} \mathrm{Zr}_{10} \mathrm{C}_{10} \mathrm{~B}_{10}$ powder blend.

Since the pressures generated in the powders are not very different in nature, it could safely be concluded that the difference in the crystallization behavior of the amorphous phases is not due to pressure. It is more probable that the composition of the five-component powder is closer to the eutectic composition in this complex system. That is why the amorphous phase in this system has transformed in a eutectic mode. Since phase diagrams for such higher-order systems are not available, and also not easy to determine, this proposition cannot be proven; it is only a conjecture at this moment.

Since we have observed mechanical crystallization of amorphous phases synthesized from blended elemental powders by MA in different Fe-based alloy compositions, and in systems with different numbers of components, it leads us to believe that mechanical crystallization is perhaps much more common than it was earlier believed to be. Thus, it may be possible in all the Fe-based powder blends that become amorphous.

\section{CONCLUSIONS}

Mechanical alloying of Fe-based powders in the quaternary $\mathrm{Fe}_{42} \mathrm{Ge}_{28} \mathrm{Zr}_{10} \mathrm{~B}_{20}$ and quinary $\mathrm{Fe}_{42} \mathrm{Ni}_{28} \mathrm{Zr}_{10} \mathrm{C}_{10} \mathrm{~B}_{10}$ powder blends resulted in the formation of a solid solution and/or intermetallic phases in the early stages of milling. An amorphous phase formed at later stages of milling. However, on continued milling beyond the formation of the amorphous phase, mechanical crystallization was observed in both the powder blends. Based on the composition of the starting powder blend, primary crystallization in form of $\alpha$-Fe solid solution was noted in the $\mathrm{Fe}_{42} \mathrm{Ge}_{28} \mathrm{Zr}_{10} \mathrm{~B}_{20}$ powder blend and eutectic crystallization in the $\mathrm{Fe}_{42} \mathrm{Ni}_{28} \mathrm{Zr}_{10} \mathrm{C}_{10} \mathrm{~B}_{10}$ powder blend. Possible reasons for mechanical crystallization were discussed and it was concluded that the thermodynamic stabilities of the different competing phases are responsible for 
the observed transformations. The chemical composition of the powder blends appears to be responsible for the difference in the crystallization behavior of the two powder blends.

\section{ACKNOWLEDGMENTS}

This research work was supported in part by National Science Foundation under Grant No. DMR-0314212.

${ }^{1}$ W. Klement, R. H. Willens, and P. Duwez, Nature (London) 187, 869 (1960).

${ }^{2}$ F. E. Luborsky, Amorphous Metallic Alloys (Butterworths, London, 1983). ${ }^{3}$ C. Suryanarayana, Bull. Mater. Sci. 6, 579 (1984).

${ }^{4}$ Metallic Glasses: Production, Properties and Applications, edited by T. R. Anantharaman (Trans Tech, Aedermannsdorf, 1984).

${ }^{5} \mathrm{R}$. W. Cahn, in Materials Science and Technology: A Comprehensive Treatment, edited by J. Zarzycki (VCH, Weinheim, 1991), Vol. 9, pp. 493-548.

${ }^{6}$ Rapidly Solidified Alloys, edited by H. H. Liebermann (Dekker, New York, 1993).

${ }^{7}$ A. Inoue, Acta Mater. 48, 279 (2000).

${ }^{8}$ W. L. Johnson, MRS Bull. 24(10), 42 (1999).

${ }^{9}$ J. F. Löffler, Intermetallics 11, 529 (2003).

${ }^{10}$ A. Inoue, Bulk Amorphous Alloys: Preparation and Fundamental Characteristics (Trans Tech, Zurich, 1998), Vol. 4.

${ }^{11}$ A. Inoue, Bulk Amorphous Alloys: Practical Characteristics and Applications (Trans Tech, Zurich, 1999), Vol. 6.

${ }^{12}$ J. Shen, Q. Chen, J. Sun, H. Fan, and G. Wang, Appl. Phys. Lett. 86, 151907 (2005).

${ }^{13}$ A. Inoue, N. Nishiyama, and H. Kimura, Mater. Trans., JIM 38, 179 (1997).

${ }^{14}$ C. Suryanarayana, Prog. Mater. Sci. 46, 1 (2001).

${ }^{15}$ C. Suryanarayana, Mechanical Alloying and Milling (Dekker, New York, 2004).

${ }^{16}$ M. L. Trudeau, R. Schultz, D. Dussault, and A. Van Neste, Phys. Rev. Lett. 64, 99 (1990).

${ }^{17}$ B. Yao, S.-E. Liu, L. Liu, L. Si, W.-H. Su, and Y. Li, J. Appl. Phys. 90, 1650 (2001).

${ }^{18}$ M. Sherif El-Eskandarany, K. Aoki, K. Sumiyama, and K. Suzuki, Scr. Mater. 36, 1001 (1997).

${ }^{19}$ M. Sherif El-Eskandarany, K. Aoki, K. Sumiyama, and K. Suzuki, Appl.
Phys. Lett. 70, 1679 (1997).

${ }^{20}$ M. Sherif El-Eskandarany, K. Aoki, K. Sumiyama, and K. Suzuki, Acta Mater. 50, 1113 (2002).

${ }^{21}$ M. Sherif El-Eskandarany and A. Inoue, Phys. Rev. B 75, 224109 (2007).

${ }^{22}$ Y. He, G. J. Shiflet, and S. J. Poon, Acta Metall. Mater. 43, 83 (1995).

${ }^{23}$ W. C. Johnson, J. K. Lee, and G. J. Shiflet, Acta Mater. 54, 5123 (2006).

${ }^{24}$ U. Patil, S.-J. Hong, and C. Suryanarayana, J. Alloys Compd. 389, 121 (2005).

${ }^{25}$ C. Suryanarayana, Intermetallics 3, 153 (1995)

${ }^{26}$ G.-H. Chen, C. Suryanarayana, and F. H. Froes, Metall. Mater. Trans. A 26, 1379 (1995).

${ }^{27}$ C. Suryanarayana and M. G. Norton, X-Ray Diffraction: A Practical Approach (Plenum, New York, 1998).

${ }^{28}$ S. Sharma, R. Vaidyanathan, and C. Suryanarayana, Appl. Phys. Lett. 90, 111915 (2007)

${ }^{29}$ P. Villars and L. D. Calvert, Pearson's Handbook of Crystallographic Data for Intermetallic Phases (ASM International, Materials Park, OH, 1985).

${ }^{30}$ S. Sharma and C. Suryanarayana (unpublished).

${ }^{31}$ Y. Chakk, S. Berger, B. Z. Weiss, and E. Brook-Levinson, Acta Metall. Mater. 42, 3679 (1994).

${ }^{32}$ D. B. Miracle and O. N. Senkov, Mater. Sci. Eng., A 347, 50 (2003).

${ }^{33}$ J. Xu and M. Atzmon, Appl. Phys. Lett. 73, 1805 (1998).

${ }^{34} \mathrm{C}$. Suryanarayana, Bibliography on Mechanical Alloying and Milling (Cambridge International Science, Cambridge, 1995).

${ }^{35}$ A. Blatter and M. Von Allmen, Phys. Rev. Lett. 54, 2103 (1985).

${ }^{36}$ A. L. Greer, J. Less-Common Met. 140, 327 (1988).

${ }^{37}$ Z. H. Yan, T. Klassen, C. Michaelsen, M. Oehring, and R. Bormann, Phys. Rev. B 47, 8520 (1993).

${ }^{38} \mathrm{C}$. Michaelsen, W. Sinkler, Th. Pfullmann, and R. Bormann, J. Appl. Phys. 80, 2156 (1996).

${ }^{39}$ F. H. Froes, C. Suryanarayana, K. C. Russell, and C. M. Ward-Close, in Novel Techniques in Synthesis and Processing of Advanced Materials, edited by J. Singh and S. M. Copley (TMS, Warrendale, 1995), pp. 1-21.

${ }^{40}$ U. Köster and U. Herold, in Glassy Metals I, edited by H. J. Güntherodt and H. Beck (Springer-Verlag, Berlin, 1981), p. 225.

${ }^{41}$ M. G. Scott, in Amorphous Metallic Alloys, edited by F. E. Luborsky (Butterworths, London, 1983), p. 144.

${ }^{42}$ C. Suryanarayana, W. K. Wang, H. Iwasaki, and T. Masumoto, Solid State Commun. 34, 861 (1980).

${ }^{43}$ R. M. Davis, B. McDermott, and C. C. Koch, Metall. Trans. A 19, 2867 (1988).

${ }^{44}$ D. R. Maurice and T. H. Courtney, Metall. Trans. A 21, 289 (1990). 